\title{
OUTCOME OF STANDARD INDUCTION THERAPY WITH DAUNORUBICIN AND ARA-C (3+7) IN ACUTE MYELOID LEUKEMIA
}

\author{
ISLAM MM ${ }^{1}$, SALSABIL MA ${ }^{2}$, KHAN MA $^{3}$, AFROSE $^{3}$, ARA T ${ }^{4}$, BISWAS AR ${ }^{4}$, RAHMAN MM ${ }^{1}$, \\ FERDOUS ${ }^{1}$, AKTER $\mathrm{M}^{1}$, NAZNEEN $\mathrm{H}^{1}$, ALI $\mathrm{M}^{1}$, NAZNEEN $\mathrm{S}^{1}$, KHATUN $\mathrm{H}^{5}$, JAHAN ${ }^{6}$
}

\begin{abstract}
Acute myeloid leukemia (AML) is a clonal, malignant disease of hematopoietic tissue.Main variables precluding cure are the treatment-related mortality and relapse rates. The most common induction chemotherapy regimens in AML involve the use of cytarabine (Ara-C) and an anthracycline. It was observational study carried out in the inpatient Department of Hematology, Dhaka Medical College Hospital, Dhaka, from July 2009 to June 2014.76 newly diagnosed cases of AML patients between 15 year to 60 yearwere enrolled in this study. All patient received standard induction therapy with Daunorubicin $45 \mathrm{mg} / \mathrm{m}^{2} \mathrm{I} / \mathrm{V}$ for 3 days and Ara-C $100 \mathrm{mg} / \mathrm{m}^{2} \mathrm{I} / \mathrm{V}$ over 24 hours for 7 days. A bone marrow aspirate to assess remission status was carried out at day 28+, after the peripheral recovery. The mean age of the patients were $35.12 \pm 12.45$ years, ranging from 17 to 55 years. $68 \%$ were male and $32 \%$ cases were female. Total 34(44.7\%) patient achieved complete remission (CR), out of them 17\% had t(8:21), 5.8\% had inv16 and only 2.9\% was FLT3 positive. 26(34\%) patient achieved partial remission (PR), $11 \%$ had $t$ (8:21) and 3.8\% inv16. 13.1\% patient failed to achieve any remission (Non responder, $N R)$ and 6 patient (7.8\%) died during induction therapy. Age, performance status and cytogenetics had significant influence $(P<0.025, P<0.030$ and $P<0.003$ respectively) on the outcome. The presenting peripheral blast percent (\%) also had a significant influence $(P=0.012)$ on the outcome after induction therapy. Complete remission rate is significantly lower in our center comparing discussed study. This is probably due to lack of modern hospital facility and socio-economic condition of our patients. Cytogenetic analysis provides the most powerful independent predictor of disease outcome. To improve outcome, all the supportive measures have to be improved and more tools are required in identifying the good prognostic groups.
\end{abstract}

J Dhaka Med Coll. 2015; 24(2) : 141-145

\section{Introduction}

Acute myeloid leukemia is a hematopoietic neoplasm that is characterized by the presence of a malignant clone of myeloid cells in the bone marrow with maturation arrest at the level of blast. ${ }^{1}$ Itis the most common acute leukemia affecting adults.Information about risk factors and clinical results on outcomes after intensive chemotherapy can be helpful in assisting clinicians in decision making. Main variables precluding cure are the treatment-related mortality and relapse rates. Decisions on intensification, de-escalation and allografting rely on the ability to divide an apparently homogeneous group according to risk. The most common induction chemotherapy regimens in AML involve the use of cytarabine (Ara-C) and an anthracycline.

Cytarabine is usually administered as a continuous infusion of 100 to $200 \mathrm{mg} / \mathrm{m}^{2} /$ day for 7 days, with an anthracycline given by intravenous push daily on the first 3 days of ara-C therapy, a combination called " $7+3$." Studies performed by CALGB in the 1980s established the efficacy of this regimen for

1. Dr. Islam Mohammad Manirul, Dr. Rahman Md. Mizanur, Dr. Ferdous Jannatul, Dr. Akter Mafruha, Dr. Nazneen Humayra, Dr. Ali Mohammad, Dr. Nazneen Shahela, Asst. professor, Haematology Department, Dhaka Medical College.

2. Dr. Salsabil Masuma Ahmed, Major, Armed Forces Institute of Pathology.

3. Dr. Khan Mohiuddin Ahmed, Dr. Afrose Salma, Professor, Haematology Department, Dhaka medical College.

4. Dr. Ara Tasneem, Dr. Biswas Akhil Ronjan, Associate professor, Haematology Department, Dhaka Medical College.

5. Dr. Khatun Hazera, Specialist, Square hospital LTD.

6. Dr. Jahan Dilshad, Specialist, Appolo hospital.

Correspondence: Dr. Mohammad Manirul Islam, Haematology Department, Dhaka Medical College. Email: manirk54@yahoo.com, Cell phone: +8801715049573 
newly diagnosed AML and since then has been the most commonly used induction regimen for treatment of adult patients with AML. ${ }^{2,3,4,5}$ Continuous infusion of ara-C at a dosage of 100 $\mathrm{mg} / \mathrm{m}^{2}$ has been shown to be superior to pulse doses of $100 \mathrm{mg} / \mathrm{m}^{2}$ every12 hours. ${ }^{2 "} 7+3$ " has been shown to be superior to the same drugs given over 5 days and 2 days $(5+2)$, respectively, ${ }^{2}$ and appears equivalent to " $10+$ 3." Increasing the ara-C dose in " $7+3$ " from $100 \mathrm{mg} / \mathrm{m}^{2} /$ day to $200 \mathrm{mg} / \mathrm{m}^{2} /$ day orprolonging the infusion to 10 days, in combination with daunorubicin, increased the toxicity with no to minimal improvement in efficacy. ${ }^{4,5,6}$ Among the chemotherapy regimens, Daunorubicin and Ara-C (“ $3+7$ ") is the gold standard; but its response has not been evaluated in our population and ethnic diversity. Keeping this in view, this study will be undertaken to analyze the response in new AML patients admitted in Dhaka Medical College Hospital (DMCH), Dhaka.The aim of the present study was to evaluate the morphological remission status after induction therapy and find out association between patients factors with the outcome of induction therapy.

\section{Methods}

It wasobservational study carried out in the inpatient the Department of Hematology, Dhaka Medical College Hospital, Dhaka, from July 2009 to June 2014.76 newly diagnosed cases of AML patients between 15 year to 60 yearwere enrolled in this study. The diagnosis was based on morphological examination of peripheral blood film and bone marrow examination and all patient received standard induction therapy with Daunorubicin $45 \mathrm{mg} /$ $\mathrm{m}^{2} \mathrm{I} / \mathrm{V}$ for 3 days and Ara-C $100 \mathrm{mg} / \mathrm{m}^{2} \mathrm{I} / \mathrm{V}$ over 24 hours for 7 days. Abone marrow aspirate to assess remission status was carried out at day $28+$, after the peripheral recovery.

\section{Selection Criteria:}

Inclusion criteria

1. Previously untreated newly diagnosed cases of AML. The diagnosis was based on morphological examination of peripheral blood film and bone marrow examination.
2. Age of the patients between 15 years to 60 years of both sex.

3. Absence of severe cardiac diseases precluding use of anthracyclines.

\section{Exclusion criteria:}

1. Secondary AML

2. History of prior chemotherapy.

3. Acute promyelocyteleukaemia

4. Age less than 15 years of both sexes.

5. Age more than 60 years of both sexes.

6. Patients who have cardiac disease.

7. Patients who could not provide supportive therapy.

8. Pregnancy in $1^{\text {st }}$ trimester.

\section{Data Collection:}

Relevant clinical data were recorded inthe structured questionnaire after written consent. It includes background information on age, sex, positive physical examination findings, laboratory investigations.

\section{Results}

The mean age of the patients were $35.12 \pm 12.45$ years, ranging from 17 to 55 years. Majority $(32 \%)$ of the patients were in the range of 31 40 years, $88 \%$ patients fell under 50 years, only $12 \%$ patients were over 50 years.68\% were male and $32 \%$ cases were female presented with generalized weakness \& tiredness ( $80 \%$ ), fever $(72 \%)$, bleeding $(34 \%)$, bodyache $(24 \%)$. all the patients presented with moderate to severe anaemia (100\%), and most of them had bone tenderness (56\%), hepatomegaly \& splenomegaly (24\%), lymphadenopathy $(20 \%)$, purpura (16\%) and gum hypertrophy (12\%). Gum hypertrophy was mostly found in patients with M4/M5 variety. Majority of the patient belonged to M2 (36\%) Variety, 24\%patients had M4, while M0, M1, M5 and M6 subtype was 4\%, 16\%, 12\% and $8 \%$ respectively. $56 \%$ of the patient had ECOG I, followed by ECOGII $\& 0$ was $36 \%$ and $8 \%$ respectively. The $\mathrm{Hb}$ conc. was found at study entry between 3.30 to $10.80 \mathrm{gm} / \mathrm{dl}$ (mean $7.00 \mathrm{gm} / \mathrm{dl})$ and most of the patients $(56 \%)$ fell within the range of $6.0-9.0 \mathrm{gm} / \mathrm{dl}$. The total 
leukocyte count (TC) was within a range between $1.3 \times 10^{9}$ and $230 \times 10^{9} / \mathrm{L}$ (mean 40.63 $\left.\mathrm{x} 10^{9} / \mathrm{L}\right)$ and most of the patients $(60 \%)$ had a TC $<25 \times 10^{9} /$ L. Platelet count varied from 3.4 $\mathrm{x} 10^{9}$ to $665 \times 10^{9} / 1\left(\right.$ mean $\left.64.87 \times 10^{9}\right)$ and $84 \%$ patients were thrombocytopenic at presentation. At presentation, blast\% was within a range between $0 \%$ to $96 \%$ (mean $51.72 \%)$ and most of the patients (56\%) had $>50 \%$ blast.

Total $34(44.7 \%)$ patient achieved complete remission (CR), out of them $17 \%$ had $\mathrm{t}(8: 21)$, $5.8 \%$ had inv16 and only $2.9 \%$ was FLT3 positive. $26(34 \%)$ patient achieved partial remission (PR), 11\% had $\mathrm{t}(8: 21)$ and $3.8 \%$ inv 16. $13.1 \%$ patient failed to achieve any remission (Non responder, NR) and 6 patient $(7.8 \%)$ died during induction therapy. Age, performance status and cytogeneticshad significant influence $(\mathrm{P}<0.025, \mathrm{P}<0.030$ and $\mathrm{P}<0.003$ respectively) on the outcome. The presenting peripheral blast percent (\%) also had a significant influence $(\mathrm{P}=0.012)$ on the outcome after induction therapy. $90 \%$ cases with CR, $16.66 \%$ cases with PR and $25 \%$ cases with NR had presented with a peripheral blast percent (\%) of less than $50 \%$. On the other hand, $83.3 \%$ cases with PR, 100\%cases with NR and 75\% caseshad a peripheral blast percent (\%)over $50 \%$.

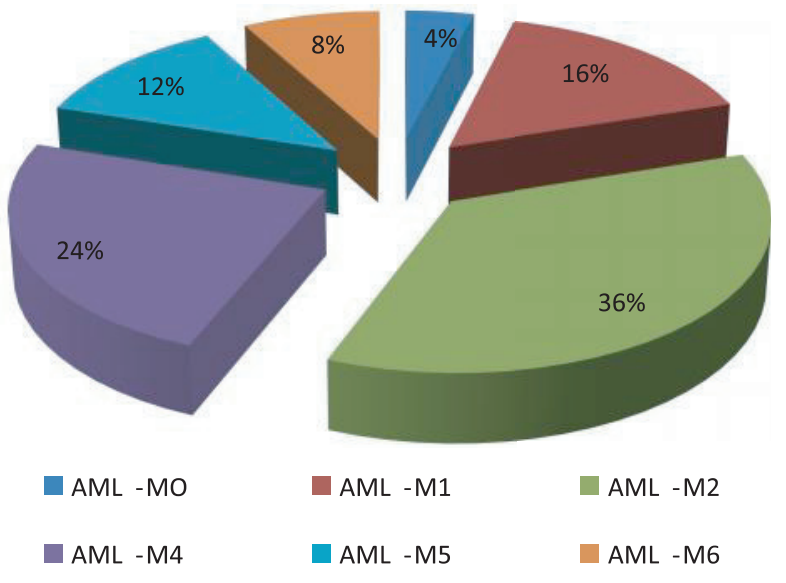

Fig.--1: Distribution of the patients by FAB classification

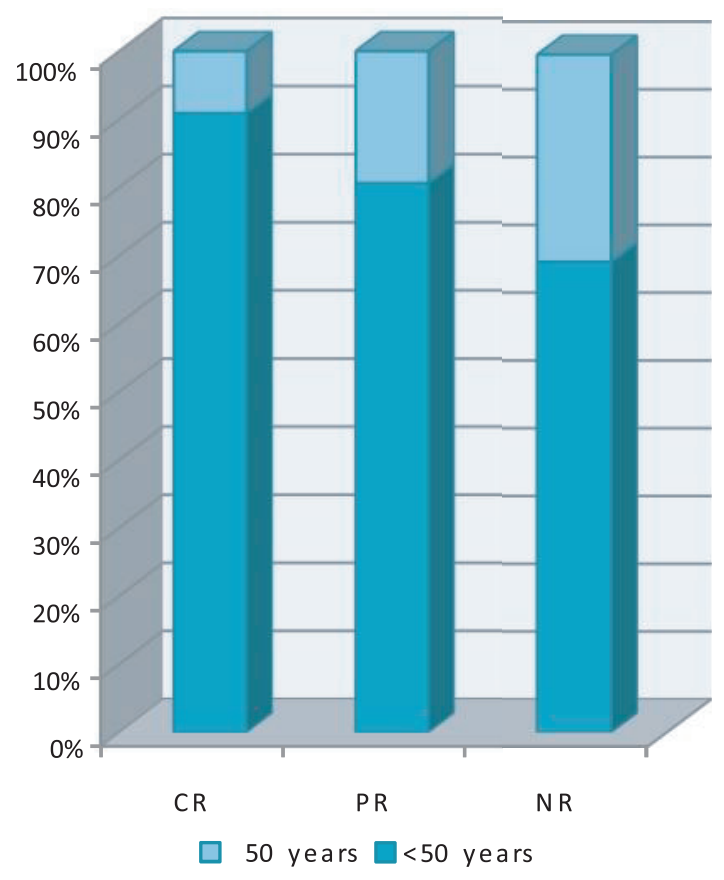

CR: Complete remission, PR: Partial remission NR: Non responder

Fig.-2: Relationship between age and treatment outcome

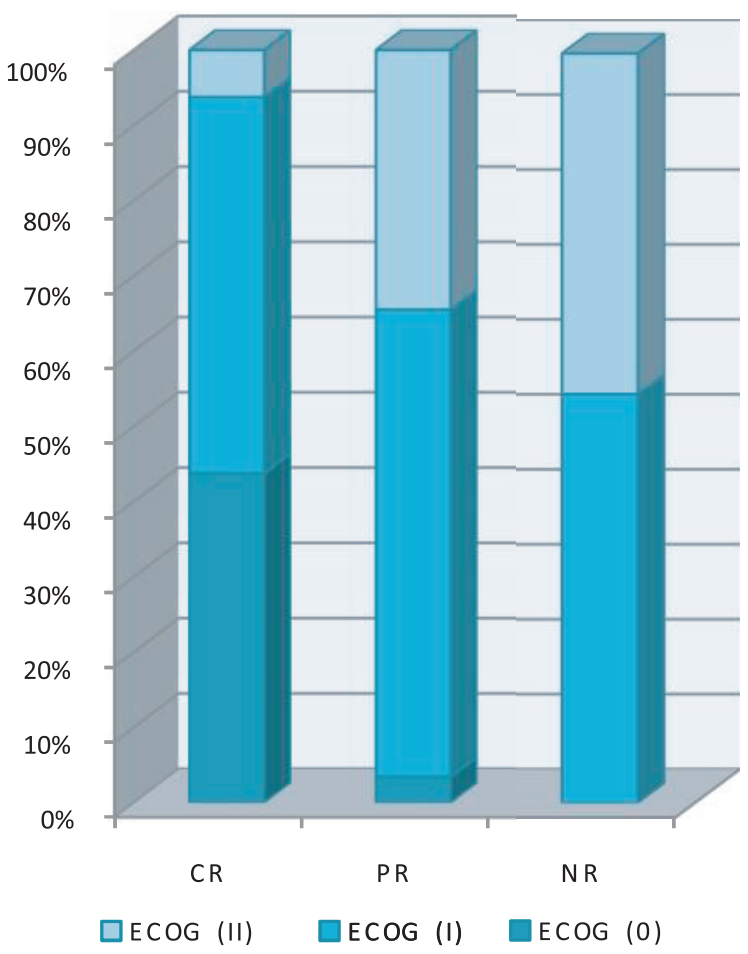

CR: Complete remission, PR: Partial remission NR: Non responder

Fig.-3: Relationship between performance status and treatment outcome 


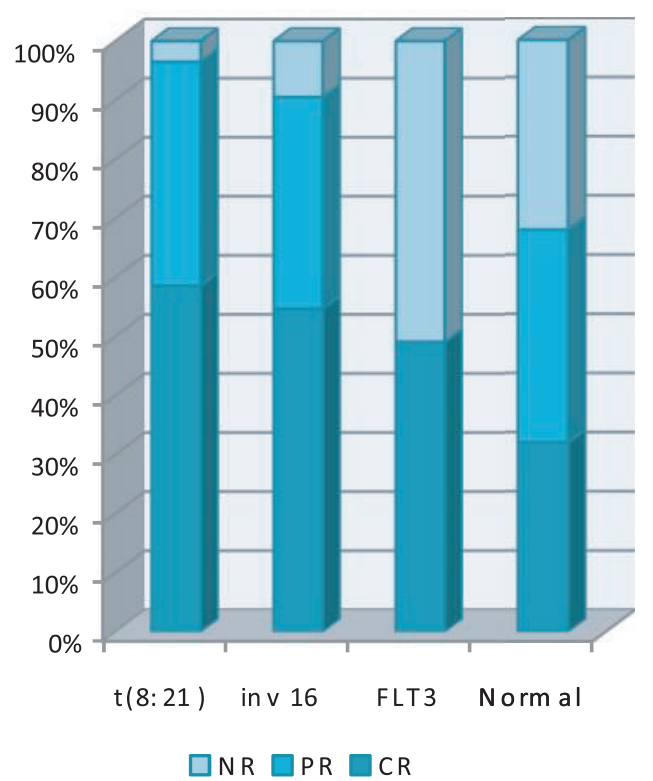

CR: Complete remission, PR: Partial remission NR: Non responder

Fig.- 4: Relationship between cytogenetics and treatment outcome

\section{Discussion}

In the present study, the mean age of the patients was $35.12 \pm 12.45$ years, while previous study in Bangladesh by Yunus ${ }^{7}$, who found 72.22 percent of AML within the age of 11-30 years and by Borua ${ }^{8}$, who found 60 percent of the AML within the age of 12-40 years. Another study in Bangladesh, Hannan ${ }^{9}$ found 62.3 percent patients were within the range of 3050 years. On the other hand, Bricker ${ }^{10}$ found median age of AML was 62-64 years, MRC ${ }^{11}$ median age was $50-55$ years, Wierniket al. ${ }^{12}$ median age was 45-50 years, Yates et al. ${ }^{3}$, median age was 48 years. These figures are much higher than our observation. This observation may be attributed to the lower number of patients are attending to the tertiary level of institution from higher age group, or more patients from younger age group opted for intensive chemotherapy, or very small non representative sample size.

Regarding sex distribution, male patients (68\%) were greater than female patients $(32 \%)$ which is more or less similar to a previous study by Yunus ${ }^{7}$ who found $72.22 \%$ male versus $27.28 \%$ female and Borua $^{8}$ who found $70 \%$ male versus $30 \%$ female. This is in contrast with the observation of Bishop et al. ${ }^{13}$ who found male $54 \%$ versus female $46 \%$ and Weinstein et al. ${ }^{14}$ who found $44.58 \%$ male versus $55.42 \%$ female. The higher incidence of AML among males in our study may be due to socio-economic status, poverty, illiteracy, female patients being neglected more and get less opportunity to attend a tertiary medical centre.

In this study, clinical feature more or less similar with the findings of Borua ${ }^{8}$ who showed weakness in $86.66 \%$, fever in $66.66 \%$, gum bleeding in $26.66 \%$, anaemia in $96.66 \%$, hepatomegaly $43.33 \%$, lymphadenopathy in $13.33 \%$, bone tenderness in $40 \%$, splenomegaly in $13.33 \%$ and purpura in $43.33 \%$.

Younger group of patient ( $<50 \mathrm{yrs}$ ) showed better outcome $(10 \% \mathrm{CR}$ versus close to $90 \% \mathrm{CR}$ in those younger) and P Value was 0.025; similar to study Preisler et al. ${ }^{4}$ andEstey et al. ${ }^{15}$ found poorer results in patients over age 50 years. Performance status also significant $(\mathrm{P}<0.030)$ which considered an important prognostic factor in AML. ${ }^{16}$ Remission rate is by far much inferior to the original study by Preisler et al. ${ }^{4}$ and Yates et al. ${ }^{3}$ found $75 \%$ CR, Cassilleth et al. ${ }^{17}$ found $70 \% \mathrm{CR}$ and Grier et al. ${ }^{18}$ reported $72 \% \mathrm{CR}$. Our Complete remission rate is significantly lower. This is probably due to lack of modern hospital facility and socio-economic condition of our patients. Being the member of least developed country, most of the patients could not bear the cost of expensive medicine and transfusion support in pancytopenic period as life supportive care.

\section{Conclusion}

The clinical outcome of acute myeloid leukemia (AML) is extremely variable, ranging from survival of a few days to cure. Different clinical and biological features at diagnosis are useful for the prediction of clinical outcome. The unfavorable biology of the disease, comorbidities, and significant side effects ofintensive cytoreductive treatment make treatment decisions difficult, and patient information becomesessential to allow a shared decision-making process. Cytogenetic analysis provides the most powerful independent predictor of disease outcome. To improve outcome, all the supportive measures have to 
be improved and more tools are required in identifying the good prognostic groups. Further large scale randomized study with a long term follow-up should be undertaken to ascertain the success of induction therapy.

\section{References}

1. Gooley TA, Chien JW, Pergam SA, et al. Reduced mortality after allogeneic hematopoietic-cell transplantation. N Engl J Med 2010;363(22):20912101.

2. Rai KR, Holland JF, Glidewell OJ, et al. Treatment of acute myelocytic leukemia: a study by cancer and leukemia group B. Blood 1981; 58(6): 120312 .

3. Yates J, Glidewell O, Wiernik P, et al. Cytosine arabinoside with daunorubicin or adriamycin for therapy of acute myelocytic leukemia: a CALGB study. Blood 1982;60(2): 454-62.

4. Preisler H, Davis RB, Kirshner J, et al. Comparison of three remission induction regimens and two postinduction strategies for the treatment of acute nonlymphocytic leukemia: a cancer and leukemia group B study. Blood 1987; 69(5): 1441-9.

5. Dillman RO, Davis RB, Green MR, et al. A comparative study of two different doses of cytarabine for acute myeloid leukemia: a phase III trial of cancer and Leukemia Group B. Blood 1991; 78(10): 2520-6.

6. Rowe JM, Tallman MS. Intensifying induction therapy in acute myeloid leukemia: has a new standard of care emerged? Blood 1997;90(6): 2121-6.

7. Yunus ABM. Chemotherapy of acute myeloblasticleukaemia with DEM regimen (Dissertation). Dhaka: Bangladesh College of Physicians and Surgeons; 1993.

8. Barua A. Prediction of response with acute nonlymphocyticleukaemia by day 6-10 marrow examination after initial induction chemotherapy (Dissertation). Dhaka: Bangladesh College of Physicians and Surgeons; 1995.

9. Hannan MA. Clinical study of leukaemia (Dissertation). Dhaka: Bangladesh College of Physicians and Surgeons; 1988.

10. Bricker H. Estimate of overall treatment results in acute nonlymphocyticleukaemia based on age -specific rates of incidence and of complete remission. Cancer Treat Rep 1985; 69:1.

11. Medical Research Council. Chemotherapy of acute myeloid leukaemia in adults. Br J Cancer 1979; 39:69-86.

12. Wiernik PH, Glidewell OJ, Hoagland HC, et al. A comperative trial of daunorubicin, cytosine arabinoside and thioguanine and a combination of three agents for the treatment of acute myelocyticleukaemia. Med PediatorOncol. 1979; 6(15):201.

13. Bishop JF, Raymond M, et al. Etoposide in acute nonlymphocyticleukaemia. Blood 1990; 75(3): 27-32

14. Weinstein HJ, Mayer RJ, et al. Treatment of acute myelogenous leukaemiain children and adults. N Engl J Med. 1980; 3(77): 473-478.

15. Estey EH, Keating MJ. Causes of initial remission induction failure in acute myelogenous leukaemia. Blood 1982; 60(23):2-11.

16. Johnson PR, Hunt LP, Yin JA. Prognostic factors in elderly patients with acute myeloid leukaemia: development of a model to predict survival. $\mathrm{Br} \mathrm{J}$ Haematol 1993;85(2):300-6.

17. Cassileth PA, Harrington DP, Hines JD, et al. Maintenance chemotherapy prolongs remission duration in adult acute nonlymphocyticleukaemia. J ClinOncol 1988; 6(9):583.

18. Grier HE, et al. Prognostic factor in childhood acute myelogenous leukaemia. J ClinOncol 1987; 5(11): 1026-1032. 